AFAPL-TR-74-16

\title{
Polymeric Pyroelectric Sensors for Fire Protection
}

\author{
U.S. Department of Commerce \\ National Bureau of Standards \\ Institute for Applied Technology \\ July 1975 \\ Technical Report AFAPL-TR-74-16 \\ NBSIR 75-728
}

FINAL REPORT FOR PERIOD JUNE 1972

TO MAY 1973

APPROVED FOR PUBLIC RELEASE

DISTRIBUTION UNLIMITED

AIR FORCE AERO-PROPULSION LABORATORY

AIR FORCE SYSTEMS COMMAND

WRIGHT-PATTERSON AIR FORCE BASE, OHIO 
When Government drawings, specifications, or other data are used for any purpose other than in connection with a definitely related Govermment procurement operation, the United States Government thereby incurs no responsibility nor any obligation whatsoever; and the fact that the Government may have formulated, furnished, or in any way supplied the said drawings, specifications, or other data, is not to be regarded by implication or otherwise as in any manner licensing the holder or any other person or corporation, or conveying any rights or permission to manufacture, use, or sell any patented invention that may be in any way related thereto.

This report has been reviewed and cleared for open publication and/or public release by the appropriate Office of Information (OI) in accordance with AFR 190-17 and DOD 5230.9. There is no objection to unlimited distribution of this report to the public at large, or by DDC to the National Technical Information Service (NTIS).

This technical report has been reviewed and is approved for publication. FOR THE COMMANDER:

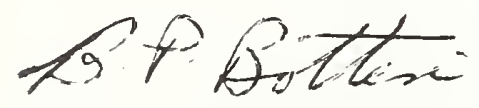

B. P. BOTTERI

Chief, Fire Protection Branch

Fuels and Lubrication Division

Air Force Aero Propulsion Laboratory

Copies of this report should not be returned unless return is required by security considerations, contractual obligations, or notice on a specific document. 


\begin{tabular}{|c|c|}
\hline REPORT DOCUMENTATION PAGE & $\begin{array}{l}\text { READ INSTRUCTIONS } \\
\text { BEFORE COMPLETING FORM }\end{array}$ \\
\hline \begin{tabular}{l|l} 
1. REPORT NUMBER & 2. GOVT ACCESSION NO. \\
AFAPL-TR-74- 16 &
\end{tabular} & 3. RECIPIENT'S CATALOG NUMBER \\
\hline \multirow{2}{*}{$\begin{array}{l}\text { 4. TITLE (and Subtitte) } \\
\text { POLYMERIC PYROELECTRIC SENSORS FOR FIRE } \\
\text { PROTECTION }\end{array}$} & $\begin{array}{l}\text { S. TYPE OF REPORT \& PERIOD COVERED } \\
\text { Final }\end{array}$ \\
\hline & 6. PERFORMING ORG. REPORT NUMBER \\
\hline 7. AUTHOR(s) & 8. CONTRACT OR GRANT NUMBER(s) \\
\hline 9. PERFORMING ORGANIZATION NAME AND ADDRESS & $\begin{array}{l}\text { 10. PROGRAM ELEMENT, PROJECT, TASK } \\
\text { AREA \& WORK UNIT NUMBERS } \\
30480761\end{array}$ \\
\hline \multirow{4}{*}{$\begin{array}{l}\text { 11. CONTROLLING OFFICE NAME AND ADDRESS } \\
\text { Air Force Aero PropuTsion Laboratory } \\
\text { Fire Protection Branch (AFAPL/SFH } \\
\text { Wright-Patterson AFB, Ohio } 45433 \\
\text { 14. MONITORING AGENCY NAME \& ADDRESS(it different from Controlling Offtce) }\end{array}$} & $\begin{array}{l}\text { 12. REPORTDATE } \\
\text { July } 1975\end{array}$ \\
\hline & $\begin{array}{l}\text { 13. NUMBER OF PAGES } \\
27\end{array}$ \\
\hline & $\begin{array}{l}\text { 15. SECURITY CLASS. (of this report) } \\
\text { UNCLASSIFIED }\end{array}$ \\
\hline & $\begin{array}{l}\text { 15a. DECLASSIFICATION/DOWNGRADING } \\
\text { SCHEDULE }\end{array}$ \\
\hline
\end{tabular}

Approved for Public Release; Distribution unlimited

17. DISTRIBUTION STATEMENT (of the abstract entered in Block 20, if different from Report)

18. SUPPLEMENTARY NOTES

19. KEY WORDS (Continue on reverse side if necessary and identlfy by block number)

Heat detector; infrared detector; optical radiation sensor; poling; Dolymer; polyvinyl fluoride; polyvinylidene fluoride; pyroelectric effect; relative spectral response; ultraviolet detector

20. ABSTRACT (Continue on reverse side if necessary and identify by block number)

This report summarizes the results of a program to develop optical radiation sensors for fire detection using polymeric pyroelectric sensing elements. Emphasis has been placed on techniques for constructing such devices, including methods of enhancing the pyroelectric response. Materials investigated included polyvinyl fluoride (PVF) and polyvinylidene fluoride $\left(P^{2} F_{2}\right)$. Six sensors were developed and delivered to the sponsor. 
13. ABSTRACT, CONTINUED

Highlights reported include achievement of a value of specific detectivity, $D^{*}$, of $2 \times 10^{8} \mathrm{~cm} \cdot \mathrm{Hz}^{1 / 2} \cdot \mathrm{W}^{-1}$ and the construction of a set of sensors usef:'? over a wavelength range extending from the ultraviolet to the infrared.

Methods of characterizing the performance of sensor elements are described. 
FOREWORD

This is the final Technical Report prepared by the Instrumentation Applications Section of the National Bureau of Standards. The effort was sponsored by the Air Force Aero-Propulsion Laboratory, Air Force Systems Command, Wright-Patterson AFB, Ohio, under MIPR No. FY 14557200412 for the period June 1972 to May 1973. The work herein was accomplished with FY72 Air Force Aero-Propulsion Laboratory Directors' funds. The work was accomplished under Project 3048, Task 304807, Work Unit 30480761 (Polymeric Pyroelectric Sensors for Fire Detection), with Mr. Terry M. Trumble as Project Engineer. Mr. Julius Cohen and Mr. Seymour Edelman of the National Bureau of Standards were technically responsible for the work.

This report presents results of a preliminary study. A number of uncertainties remain that should be considered in more detail. Therefore, the conclusions are not necessarily those that would be reached in a full complete investigation. 
POLYMERIC PYROELECTRIC SENSORS

FOR FIRE PROTECTION

Table of Contents

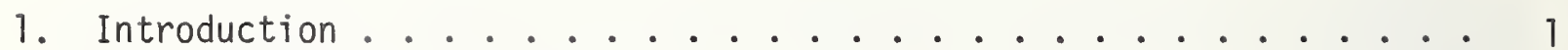

1.1 Background .................... 1

1.2 Objectives and Tasks ................ 1

2. Experimental Development ............. 2

2.1 Materials Selection .............. 2

2.2 Poling Methodology ............. 3

2.3 Experimental Investigation of Poling Parameters . . . . . 4

2.4 Characterizing Sensor-Element Performance ........ 5

2.5 0ther Investigations ............. 8

3. Deliveries .................... 9

4. Summary and Conclusions .................. 10

5. Recommendations for Further Work ............. 11

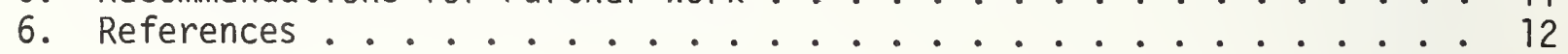


Figure 1: Block Diagram of Apparatus Used to Monitor Poling Effectiveness ............... 14

Figure 2: Poling Fixture . . . . . . . . . . . . . . . 15

Figure 3: Relative Response of a $\mathrm{PVF}_{2}$ Sample as a Function

of Poling Temperature for Three Poling Fields . . . . . . 16

Figure 4: Relative Response of a PVF 2 Sample as a Function of Time After the Poling Field is Removed. . . . . . . . . 17

Figure 5: Relative Polymer Pyroelectric Response as a Function of the Reciprocal of the Poling Field . . . . . 18

Figure 6: Relative Polymer Pyroelectric Response as a Function of the Reciprocal of the Poling Field . . . . . . . . . 19

Figure 7: Relative Polymer Pyroelectric Response as a Function of the Reciprocal of the Poling Field.......... 20

Figure 8: Relative Polymer Pyroelectric Response as a Function of the Reciprocal of the Poling Field . . . . . . . . 21

Figure 9: Relative Polymer Pyroelectric Response as a Function of the Reciprocal of the Poling Field . . . . . . . . 22

Figure 10: Circuit of Voltage Preamplifier Used in Relative Pyroelectric Response Measurements .............. 23

Figure 11: Relative Spectral Response of a Mounted PVF Sensing Element as a Function of Wavelength ........... 24

Figure 12: Relative Spectral Response of a Mounted $\dot{P V F}_{2}$ Sensing Element as a Function of Wavelength........ 25

Figure 13: Sensor Construction . . . . . . . . . . . 26 Figure 14: Circuit of Preamplifier Used in Blackbody Determinations of Specific Detectivity, ${ }^{*}{ }_{B B}$............ 27 
. 


\section{INTRODUCTION}

Radiation sensors have proved to be among the most rapidly responding devices for the detection of flames. The application of radiation sensors to aircraft has been limited primarily to engine nacelle installations, where temperatures vary from 90 to $430^{\circ} \mathrm{C}$. Crew areas, cargo compartments, baggage compartments, and passenger areas have had little, if any, protection. The work reported was undertaken at the request of the sponsoring agency to develop low-cost, highly sensitive sensors with high specificity for use in these critical aircraft areas. Such sensors would also have extensive application in groundsupport facilities.

Polymeric sensors proposed to meet program requirements should contribute to the realization of inexpensive, reliable radiation-sensing systems for Air Force use.

\subsection{Background}

Certain polymers, e.g., polyvinyl fluoride (PVF) and polyvinylidene fluoride $\left(P F_{2}\right)$, may be made to exhibit significant pyroelectric activity by means of a poling process. Usually poling consists of applying an intense electric field at an elevated temperature and cooling to room temperature with the field still applied. When the pyroelectrically active material is subjected to a small temperature change, charges produced on the surfaces are detectable as a voltage (open-circuit configuration) or as a current (short-circuit configuration). Thus, the pyroelectrically active polymer may be used as a detector of electromagnetic radiation. Polymeric radiation sensors can operate at room temperatures, require no biasing, have an extremely broad spectral response, and have a short response time compared to most other types of thermal detectors.

Polymeric pyroelectric sensors have advantages over conventional crystalline pyroelectric detectors because they are non-hygroscopic (and therefore easily handled), chemically inert, flexible, simply fabricated into large-area devices, and made from relatively inexpensive materials. These properties rerider polymeric sensors attractive for fire-protection applications.

\subsection{Objectives and Tasks}

The statement of work establishing the project defined the objective as "To design and build operable pyroelectric sensors capable of being used for detecting emission from combustion processes at 4.5, 7.2, and 10 microns, as we 11 as in the 200 to 300 nanometer region." 
The effort was to consist of the following tasks:

(1) Experimental selection of polymeric materials susceptible to treatment for developing significant pyroelectric activity;

(2) Processing of selected polymeric materials to induce significant pyroelectric activity - i.e., by means of poling - with a view towards achieving maximum pyroelectric activity for each specific material;

(3) Development of instrumentation for reliable measurement of detectivity; and

(4) Construction of sensors together with measurement of detectivity and relative spectral response for each device.

The goal was to produce sensors with values of specific detectivity $D^{*}$, equal to or greater than $10^{8} \mathrm{~cm} \cdot \mathrm{Hz}^{1 / 2} \cdot \mathrm{W}^{-1}$.

\section{EXPERIMENTAL DEVELOPMENT}

\subsection{Materials Selection}

The pyroelectric responses of a number of polymers were compared qualitatively. This operation was a rapid screening to select the best readily available material for development for thermal radiation sensors. Selection was restricted largely to cornmercially available materials because preparation of material in the large quantities needed for adequate testing would have been prohibitively expensive and time-consuming. As a first cut, materials were selected containing a significant number of permanent dipoles capable of being oriented. So-called crystallinity was not considered a necessary property, although most of the materials selected had this property. The materials investigated included polyethylmethacrylate (PEMA), fluorinated ethylene propylene (FEP), cellulose acetate (CA), polyvinyl chloride (PVC), polyvinyl fluoride (PVF), polyvinylidene fluoride ( $P V F_{2}$ ), and special research samples of polyphosphazenes (PPZ) prepared at no cost to the project by a commercial laboratory. Although each material was selected for various properties, there was a principal reason for selecting each. Specifically, PEMA was chosen because it softens at a relatively low temperature, which may simplify poling; FEP was chosen because of its large dipole moment; CA was tried because it is a derivative of wood previously found by others to have piezoelectric properties [1]+; PVC, PVF, and $\mathrm{PVF}_{2}$ were chosen because these materials possess a comparatively large number of permanent dipoles per unit volume and exhibit substantial piezoelectric activity $[2,3]$, and PVF and PVF 2 in addition exhibit substantial pyroelectric activity $[4,5,6,7,8]$; PPZ was tried because it is also a polar material.

Samples of these materials were processed by various mechanical, thermal, and electrical means, or by a combination of these, in an effort to enhance pyroelectric activity. Some activity was developed in most of the samples tested. The samples of PVF and PVF 2 showed greatest activity. The outputs of two of the special polyphosphazene samples too thick for convenient use as pyroelectric

tFigures in brackets refer to references, section 6 . 
material were noticeably better than those obtained with any samples other than PVF and $\mathrm{PVF}_{2}$, although the samples lacked sufficient dielectric strength to allow poling fields comparable to those used on the other samples.

(Further experimentation with the polyphosphazene formulation and with the methods used to form the samples is warranted.) The pyroelectric response found for PVF and PVF 2 was so much greater than the activity found for other polymers that all further efforts were devoted to these two materials. The form in which they were available for sensor development was as thin films,

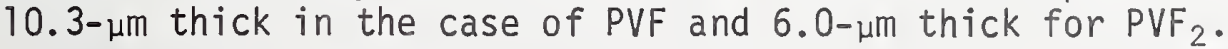

\subsection{Poling Methodology}

Because the methods used to manufacture PVF and PVF 2 are considered proprietary by some suppliers, it has not been possible to learn the past history of the samples used in this project. In particular, little information or stretching modes and the possible application of electric fields during processing has been available. Most polymeric materials as received from commerical sources require poling in order to enhance existing pyroelectric activity or to develop new activity to useful levels.

2.2.1 Uniaxial Stretching. For PVF $_{2}$ a preliminary step to the poling process was in some cases uniaxial stretching. As used in this report, uniaxial stretching refers to an intentional process applied to as-received material.

The polymer sheet as received was assumed to be predominantiy in the $\alpha$ form, that is, as described in one model, with molecules in a trans-gauch-transgauch-primed configuration in which the electric dipoles were approximately parallel to the axis of the molecule. According to this model, uniaxial stretching in the direction of the chain axis converts some proportion of the molecules into a $\beta$ form in which the chain is extended to be an almost planar zig-zag, and the dipoles are therefore nearly perpendicular to the chain axis and hence to the plane of the polymer film $[9,10]$. The $\beta$ phase is thought to be more amenable to poling as the dipoles of interest are preferentially aligned to be parallel or anti-paraliel with the perpendicular to the chain axis. The assumption is that an electric field applied to the uniaxially stretched polymer tends to orient the dipoles, perhaps by rotation of the chain axis.

2.2.2 Application of Electrodes. Apart from uniaxial stretching of certain PVF $_{2}$ samples, a preliminary operation in the poling process was the vacuum deposition of metal-film electrodes. For the pyroelectric sensor work, a visually semitransparent nickel coating about 20-nm thick was deposited on the front surface of the sensor (i.e., the surface intended to be facing a source) with a 50- to 80-nm coating on the rear surface. These coatings served both as electrodes and as absorbers. Both PVF and PVF 2 are transparent in the spectral region of primary interest. Absorbing layers were therefore required to convert a change in the amount of radiation incident on the polymer into a change in the polymer temperature. The upper limit to the thickness of the front-surface coating was determined by the 
requirements that the amount of energy reflected away from the sensor be minimized and that a reasonable proportion of the energy reach the rearsurface coating. The lower limit was determined by the requirements that some absorption take place in the front-surface coating and that the coating be electrically conductive, and by 1 imitations in the minimum thickness that could be reproducibly deposited with available equipment. (Thickness of the deposited layer was monitored with a commercial instrument during the deposition process. The sensor head of this instrument was mounted in the vacuum chamber at the same distance from the evaporative source as the polymer film and close to it; the measuring principle of the instrument used depends on the shift in resonant frequency of a sensing crystal as the mass of the crystal is increased by the portion of evaporated material it intercepts.)

2.2.3 Poling. The poling cycle used consisted of applying the poling field at room temperature, raising the temperature to some pre-determined maximum, maintaining the maximum temperature (the poling temperature) for approximately 30 min, and cooling to room temperature before the field was removed.

Thermostatically controlled laboratory ovens provided heating. Poling temperatures used in this work ranged from 90 to $130^{\circ} \mathrm{C}$, with room temperature about $20^{\circ} \mathrm{C}$. Poling fields ranged from 300 to $800 \mathrm{kV} \cdot \mathrm{cm}^{-1}$, applied across the thickness of the polymer film. For some samples, multiple poling cycles were used with successively higher field strengths.

The poling process was monitored by measuring sensor-element response using the arrangement shown in figure 1. This system is analogous to one that has been used to monitor piezoelectric activity of polymers during poling [11]. Each polymer-film element was mounted in a fixture as shown in figure 2. (The fixture was adapted from one developed by Phelan and Mahler [6]). Note that in this design a gap is left between the rear electrode and the fixture to minimize the tendency to arc around the edge. The field applied to the sensing element acting as detector was supplied by a bias circuit. Radiation incident on the polymer film from a 100-W zirconium arc lamp was modulated at $10 \mathrm{~Hz}$ by a mechanical chopper. The amplitude of the signal developed across the detector was measured with an oscilloscope.

\subsection{Experimental Investigation of Poling Parameters}

Experiments were conducted to provide an improved understanding of the role of the two poling parameters, temperature and field.

In one set of experiments, several samples were poled in successive cycles with increasing field strength, without being removed from the poling oven. The pyroelectric response was measured as described in 2.2. Figure 3 shows relative response as a function of temperature for three poling cycles for one sample of $\mathrm{PVF}_{2}$. The response observed with a large field applied was found to comprise a large temporary and a small quasi-permanent effect. Immediately after the field was removed after cooling to room temperature, a large decay in response was observed, followed by a more gradual decay. After several hours, a quasi-steady value was reached. The response as a function of time of a poled sample of PVF $_{2}$ is shown in figure 4. 
Ancther set of experiments was conducted in an attempt to determine the poling conditions required to maximize pyroelectric response for both PVF and PVF 2 . Several sets of sample sensing elements, each set taken from a single piece of polymer as received from the manufacturer, were poled in successive cycles with increasing field strength but with constant poling temperature for each set. After each cycle, the polymer sensing elements were removed from the oven and set aside. After a minimum of 18 hours after poling. the pyroelectric response was measured as described in 2.2.3. As mounted in a poling fixture, each sensing element had an area of $1 \mathrm{~cm}^{2}$. Measurement parameters were: measuring frequency, $10 \mathrm{~Hz}$; blackbody temperature, $500 \mathrm{~K}$; distance from blackbody aperture to sensor, $50 \mathrm{~cm}$; and equivalent noise bandwidth, $1 \mathrm{~Hz}$. The results of these experiments are plotted in figures 5 through 9, which show the logarithm of the relative pyroelectric response as a function of the reciprocal of the poling field. Figure 5 shows the plot for four samples of $\mathrm{PVF}_{2}$ poled at $90^{\circ} \mathrm{C}$; figure 6 , the plot for five samples of PVF 2 poled at $110^{\circ} \mathrm{C}$; figure 7 , the plot for five samples of $P V F_{2}$ poled at $130^{\circ} \mathrm{C}$; figure 8 , the plot for five samples of PVF poled at $90^{\circ} \mathrm{C}$; and figure 9 , the plot for four samples of PVF poled at $110^{\circ} \mathrm{C}$. For these measurements, a yoltageresponding preamplifier was used to condition the signal from the mounted sensing element. The circuit diagram of this instrument is given in figure 10 .

\subsection{Characterizing Sensor-Element Performance}

2.4.1 Spectral Response Measurements. Relative spectral response was determined with the aid of a monochromator. Figures 11 and 12 show relative response as a function of wavelength, for mounted sensing elements of PVF and $P_{2}$, respectively. The curve for PVF exhibits little dependence of response on wavelength in the region of about 6 to $18 \mu \mathrm{m}$; at longer wavelengths, however, the response rises rapidly with increasing wavelength. The response curve for PVF 2 is 1 imited to wavelengths below $10 \mu \mathrm{m}$ because of excessive noise experienced at higher wavelengths. Some of the observed noise probably results from the effect of air currents on the exposed surface of the sensing-element surface, and isolation of the sensor element from such disturbances, for example by means of an infrared transparent window, is recommended.

2.4.2 Pyroelectric Response Measurements. Pyroelectric response was measured using a commercial blackbody-type radiation source operated at $500 \mathrm{~K}$. An aperture plate in front of the source defined the source area. The radiation from the source was chopped before passing to the sensing element. For these measurements, the sensing element. was mounted in a housing to form a sensor package, shown in figure 13. Distance from blackbody aperture to sensing element was typically $50 \mathrm{~cm}$. Blackbody, chopping wheel, and sensing element were mounted on an optical bench to facilitate alignment. A commercially available, two-channel, phase-sensitive amplifier was used to measure the sensing-element output with the signal controlling the chopping wheel serving as reference. This lock-in type of amplifier was equipped with modular preamplifiers; however, for certain critical measurements, a special 
preamplifier was used. The reading from the meter driven by the phasesensitive detector circuit of the amplifier, together with instrument settings and other measurement conditions, provided information from which the pyroelectric responsivity, defined as the ratio of rms signal (sensor-output) voltage to rms value of blackbody incident signal power (on the sensor), referred to an infinite sensor load impedance and to the terminals of the sensor, could be calculated.

Responsivity is usually expressed in units of $V \cdot W^{-1}$ or $A \cdot W^{-1}$, depending on whether short-circuit current or open-circuit voltage measurements of sensor output are made.

Another parameter characterizing sensor pyroelectric performance is the specific detectivity, $D^{*}$. This quantity involves noise measurement and is given by the ratio of (1) the product of signal-to-noise ratio and the square root of the effective noise bandwidth to (2) the product of the rms blackbody power density and the square root of the sensar area. The blackbody power density, $H_{B B}$, is given by the relation [12]:

$$
H_{B B}=\frac{\varepsilon \sigma T^{4}}{\pi d^{2}} A_{B B}
$$

where $\varepsilon$ is the blackbody emissivity, $\sigma$ is the Stefan-Boltzmann constant, $T$ is the temperature in degrees $K, A_{B B}$ is the effective radiating area of the blackbody in square centimeters, and $d$ is the distance from blackbody aperture to sensor in centimeters. When the radiation is chopped, the rms value of $\mathrm{H}_{\mathrm{BB}}$ is the product of $\mathrm{H}_{\mathrm{BB}}$ and a modulation factor, 0.45 for square-wave chopping. The effective hoise bandwidth depends in part on instrument settings and is introduced, as is area, as a normalization factor. D* measured using the total irradiance from. a blackbody source may sometimes by indicated by $D^{*}$ to distinguish this parameter from $D^{*}$, which represents $D^{*}$ measured ${ }^{B}$ a single wavelength. Conventionally, the blackbody temperature and the measuring frequency are given in parentheses following the $D^{*}$ value. Although most measurements were made at a chopping frequency of $10 \mathrm{~Hz}$ and with equivalent noise baridwidth adjusted to be $1 \mathrm{~Hz}$, measurements for critical determinations of $D^{*}$ were made at $1.6 \mathrm{~Hz}$ and with an equivalent noise bandwidth of $0.1 \mathrm{~Hz}$. All measurements for critical determinations of $D^{*}$ were made with an appropriately small limiting aperture and the baffle system described in 2.4.3.1 and 2.4.3.2, respectively. Figure 14 shows the circuit of the preamplifier used in these measurements. To reduce noise, the sensing elements were isolated from air currents. Specific detectivity was found to be on the order of $10^{8} \mathrm{~cm} \cdot \mathrm{Hz}^{1 / 2}$. $\mathrm{W}^{-1}$ for the more active sensing elements made from asreceived $\mathrm{PVF}_{2}$ (i.e., from material not uniaxially stretched) poled at $800 \mathrm{kV} / \mathrm{cm}$ and $110^{\circ} \mathrm{C}$, with values as high as $2 \times 10^{8} \mathrm{~cm} \cdot \mathrm{Hz}^{1 / 2} \cdot \mathrm{W}^{-1}$ being determined. For small samples made, from uniaxially stretched PVF 2 , detectivities of up to $2.5 \times 10^{8} \mathrm{~cm} \cdot \mathrm{Hz} / 2 \cdot \mathrm{W}^{-1}$ have been determined. For PVF, typical detectivity values were on the order of $10^{7} \mathrm{~cm} \cdot \mathrm{Hz}^{1 / 2}$. $\mathrm{W}^{-1}$ for a sensing element poled at $500 \mathrm{kV} / \mathrm{cm}$ and $90^{\circ} \mathrm{C}$. 
A study of the uniformity of response across the surface of a sensing element made from uniaxially stretched PVF $_{2}$ indicated that detectivity values even higher than the highest value given above have been attained over small regions. A laser beam about $1 \mathrm{~mm}$ in diameter was used to scan the sensitive area of the sensor in small increments. It was found that on the order of $90 \%$ of the response was developed in an area no greater than that covered by the beam. The entire sensitive area had a diameter of $1 \mathrm{~cm}$. The suggestion was made that the variation of response with position was due to nonuniform uniaxial stretching.

2.4.3 Sources of Error in Pyroelectric Response Measurements. The sources of error investigated were imperfections in the simulated blackbody source and stray radiation. The latter is a particularly crucial consideration for pyroelectric detectors, and for thermal detectors in general, because their broad spectral response makes them sensitive to radiation from relatively low temperature sources.

2.4.3.1 As a first step, response of a sensor to a series of power levels, which were determined by limiting blackbody apertures of different known areas, was observed. Results showed large departures from linearity. To investigate uniformity of emission over the aperture of the blackbody source, measurements were made using a lead sulfide photoconductive detector. Since this photon detector cuts off rapidly above approximately $3 \mu \mathrm{m}$, sensitivity is confined to the hotter areas of the source. The need for concern with stray radiation from objects that may be warmed by proximity to the source such as the chopper and the limiting apertures is avoided.

Varying source-to-detector distance and comparing the measured response with that predicted on the basis of the inverse square relation of power with distance provided a relative calibration of the lead sulfide detector response and confirmed the linearity of this response. Following this check, the various apertures were successively introduced in front of the blackbody, and the available power was measured with the detector. Results showed good agreement with a linear relationship of power to aperture area over the range of aperture diameters from $0.32 \mathrm{~cm}$ to $1.27 \mathrm{~cm}$. No apertures with diameters smaller than $0.32 \mathrm{~cm}$ were used. Emission through a limiting aperture of 1.59 $\mathrm{cm}$ was lower than that called for by the linear relationship. With no limiting aperture inserted, the radiation was emitted from the opening of the blackbody itself. The nominal diameter of this opening was $1.6 \mathrm{~cm}$. Emission with no aperture, however, was much greater than that called for by the linear relationship. The excess was attributed to radiation transmitted through the plastic liner that serves to define the $1.6 \mathrm{~cm}$ opening in the blackbody. Subsequent measurements of the response of pyroelectric sensors were performed with limiting apertures of no greater diameter than $1.3 \mathrm{~cm}$.

2.4.3.2 The existence of stray radiation also interfered with measurements of pyroelectric sensor response. Three important sources of such radiation were the aperture disk, the blackbody housing and support bracket, and the chopping 
wheel blades. Cooling the aperture disk with forced air or water (coldstopping) is the method commoniy used to eliminate stray radiation for measurements of photon-detection response for wavelengths beyond $10 \mu \mathrm{m}$. This method may not be practical for measurements extending into the far infrared, especially when large-area sources of stray radiation are present, because the decrease in power density achieved by lowering the temperature of the contributing stray sources is not sufficient to overcome the effect of the sources.

The technique used in these measurements to minimize the effects of stray radiation from both the aperture disk and the blackbody (including bracket) was as follows: a baffle plate with provision for mounting aperture disks was constructed and positioned in front of the blackbody so that only the cavity itself could be seen by the pyroelectric sensor. The chopping wheel was repositioned to be in the space between blackbody and baffle plate, so that chopping of the radiation took place behind the aperture and therefore neither aperture nor baffle, even if slightly heated, could contribute to producing a spurious sensor output.

A second baffle was constructed and positioned near the first to provide a degree of collimation to radiation from the chopping-wheel blades so that when a blade was in line with the aperture, the sensor could see an area of the blade only slightly larger than that of the aperture. A given spot on a blade spends only a small fraction of the time required for one revolution of the chopping wheel in front of the blackbody cavity (when it is heated by blackbody radiation) and is small compared to the blade. Each such spot has the opportunity to $\mathrm{cool}$ to near room temperature before it returns to a position in line with the blackbody cavity. That the baffle system is effective was confirmed by the observation that reducing the size of the aperture (and, therefore, the effective radiating area of the choppingwheel blades) did not have any significant effect on measured sensor responsivity, with all the other conditions held constant.

Following the introduction of the baffle system, measurements were made with various apertures in place and with a pyroelectric sensor instead of the photon detector. Agreement was obtained between measured sensor response and that predicted on the basis of the change in blackbody aperture. Extrapolation of the data indicated that at zero power the responsivity should be nearly zero, further confirming that effects of stray radiation were not significant with the baffles in place.

\subsection{Other Investigations}

2.5.1 Experiments with ULtraviolet-Absorbing PVF. Experiments were carried out with special samples of ultraviolet-absorbing PVF to determine the suitability of this material for use as an ultraviolet sensor. Sensors constructed from this material were found qualitatively to be more sensitive to radiation in the ultraviolet than sensors constructed in the same manner from either 
"ordinary" PVF (which exhibits nearly no response to ultraviolet) or "ordinary" $\mathrm{PVF}_{2}$ (slight response). Initial attempts to obtain quantitative responsivity data with the aid of a calibrated ultraviolet lamp were not successful because of poor signal-to-noise ratio as measured at the phase-sensitive amplifier. A possible source of noise was long-wavelength radiation from the chopper blades. However, other noise sources were probably contributing to poor signal-tonoise ratio, and it was clear that a more powerful calibrated source was required. Such a source was not available within the time constraints of the project, and no further work was done in the ultraviolet region.

2.5.2 Sersors Tailored for Specific Wavelengths. Experiments were conducted to investigate the feasibility of constructing polymer-film sensors which would respond only to, or primarily to, selected wavelengths. Results from this experimentation together with consultation with experts in the deposition of metal films and dielectric coatings led to the recomendation that a useful approach would be to use a pass-band filter in front of the sensor and to compensate as much as possible for the losses in the filter by coating the sensing-element surface with an absorbing film. Gold black was selected as an absorber, and trial coatings have been successfully deposited, both on the polymer directly and on nickel electrodes. Time did not permit further work on tailored-response sensors.

\section{DELIVERIES}

Six sensors were ciesigned, constructed, measured, and delivered to the sponsor. One sensor is active in the $200-$ to $300-n m$ region. The other five are active in the infrared region and can be peaked by the use of suitable filters.

Two PVF sensors with a measured $D^{*}(500 \mathrm{~K}, 1.6 \mathrm{~Hz})$ of more than $10^{7} \mathrm{~cm} \cdot \mathrm{Hz}^{1 / 2}$. $W^{-1}$ were delivered early in the course of this project. Four sensors representing further advancement in development were delivered near the end of the project; pertinent characteristics are given in table 1.

Table 1

Characteristics of Four Experimental Sensors Delivered to Sporisor

Material

Area

$\left(\mathrm{cm}^{2}\right)$

Specific Detectivity, $D^{*}(500 \mathrm{~K}, 1.6 \mathrm{~Hz})$

$\left(\mathrm{cm} \cdot \mathrm{Hz} 1 / 2 \cdot \mathrm{W}^{-1}\right)$

U1traviolet-Absorbing

PVF

$\mathrm{PVF}_{2}$

$\mathrm{PVF}_{2}$

$\mathrm{PVF}_{2}$

+No value of $D^{*}$ could be determined, because of the presence of noise and other experimental difficulties as described in 2.5.1. A definite response was observed. 


\section{SUMMARY AND CONCLUSIONS}

Films of PVF 2 were poled by applying a static electric field (300 to $800 \mathrm{kV} / \mathrm{cm}$ ) across the films at temperatures in the range 90 to $130^{\circ} \mathrm{C}$ followed by cooling to room temperature with the field maintained.

Results generally suggest that the greater the poling field, the greater the ensuing pyroelectric responsivity. However, for $\mathrm{PVF}_{2}$ the responsivity is a sensitive function of both poling field and temperature. An intrepretation of the hysteresis in relative response shown in figure 3 is that the relative response is proportional to the alignment of dipoles. For the lower curve (field of $300 \mathrm{kV} / \mathrm{cm}$ ), it appears that a temperature greater than about $60^{\circ} \mathrm{C}$ is required to obtain a significant alignment of the dipoles by the field. The hysteresis of the curves is believed to be a manifestation of the increased polarization produced by the applied field during the rising portion of each temperature cycle.

An interpretation of the temporal response curve of figure 4 is that the response observed with a large field applied comprises a large temporary effect and a smaller quasi-permanent effect. Immediately on removing the field (after cooling to room temperature), there is a very large decay in response, followed by a more gradual decay. After several hours a nearly steady value is obtained. The effects are presumed to result from increased dipole alignment and from surface charges. The initial large decay upon removal of the field is attributed to partial dipole realignment while the gradual decay is attributed to charge leakage. The quasi-permarient effect that remains is postulated to be produced by dipoles that retain their orientation after the field is removed.

Examination of figures 5,6 , and 7 reveals an exponential relationship between responsivity and reciprocal field, relatively small scatter between samples from a single piece of material, higher responsivity after using higher poling fields, and, apparently, more effective poling at $100^{\circ} \mathrm{C}$ than at $90^{\circ} \mathrm{C}$ or $730^{\circ} \mathrm{C}$, particularly at the higher fields. For PVF, examination of figure 8 shows large scatter in responsivity between samples, while in figure 9 the scatter shown is much less. Both figures show comparative insensitivity of responsivity to poling field above approximately $400 \mathrm{kV} / \mathrm{cm}$ (reciprocal of field $=2.5 \times 10^{-6} \mathrm{~cm} / \mathrm{V}$ ) and $90^{\circ} \mathrm{C}$. The responsivity attained in this material by poling at relatively low field and temperature is comparable to that of PVF $_{2}$ after poling at appreciably higher temperature and higher fields. Within the limits of field, temperature, and number of samples used in this study, optimum poling for PVF 2 appears to be obtained with a field of $800 \mathrm{kV} / \mathrm{cm}$ (reciprocal of field $=1.25 \times 10^{-6} \mathrm{~cm} / \mathrm{V}$ ) and a temperature of $110^{\circ} \mathrm{C}$ for PVF, optimum poling conditions are a field of 350 to $300 \mathrm{kV} / \mathrm{cm}$ (reciprocal of field $=2.86 \times 10^{-6} \mathrm{~cm} / \mathrm{V}$ ) and a temperature of $110^{\circ} \mathrm{C}$.

The most responsive $\mathrm{PVF}_{2}$ samples were uniaxially stretched before electrodes were applied. As discussed in 2.2.1, uniaxial stretching of $\beta$-phase material is thought to orient molecular chains in the plane of the sample. It is assumed that for $\beta$-phase material the electric field applied normal to the 
film plane after stretching orients the dipoles, resulting in polarization which is retained when the specimen is cooled. For stretched and electrically poled PVF $_{2}$, pyroelectric coefficients approaching those of triglycine sulfate, a material commoniy used for IR detectors, have been obtained.

Sensors containing polarized PVF or $\mathrm{PVF}_{2}$ with sensitive elements $1 \mathrm{~cm}^{2}$ in area were constructed and $D^{*}(500 \mathrm{~K}, 1.6 \mathrm{~Hz})$ was measured. A typical value of $D^{*}$ for $P_{V F}$ was about $10^{8} \mathrm{~cm} \cdot \mathrm{Hz}^{1 / 2} \cdot \mathrm{W}^{-1}$, and for $\mathrm{PVF}, 10^{7} \mathrm{~cm} \cdot \mathrm{Hz}^{1 / 2} \cdot \mathrm{W}^{-1}$.

The relative spectral response of a PVF sensing element (figure 11) showed little dependence on wavelength in the region to 6 to $18 \mu \mathrm{m}$; the 1 imited data obtained at higher wavelengths indicated that the response increased rapidly with increasing wavelength, at least to $25 \mu \mathrm{m}$, the maximum studied. The relative spectral response of a PVF 2 sensing element measured in the region of 1 to $10 \mu \mathrm{m}$ (figure 12) showed maxima and minima.

Sensors made with ultraviolet-absorbing PVF were found to respond in the ultraviolet more strongly than either "ordinary" PVF or PVF 2 . No quantitative measurements were made.

\section{RECOMMENDATIONS FOR FURTHER WORK}

The results reported here support the expectation that significant improvement of sensor performance in regard to detectivity can be made. To achieve this potential improvement, the following further work is recommended:

(1) Continue investigations of the effect of stretching on PVF and $\mathrm{PVF}_{2}$, particularly uniaxialiy stretched samples of the latter which have exhibited very high responsivities in small areas only. Furtrier work is needed to develop techniques to permit stretching uniformly over large areas. Methods of determining or identifying areas of uniform stretch are required. An optical method suggested in the course of the project may have promise.

(2) Experiment with other potential sensor materials, such as the polyphosphazenes. A preliminary trial conducted earlier suggests the possibility of responsivities comparable to those measured for PVF and $\mathrm{PVF}_{2}$.

(3) Identify and, if possible, reduce major sources of noise.

(4) Experiment with new methods of poling, such as pulsing the field or applying the field during the stretching operation.

(5) Improve detector construction to reduce stray capacitance and thus increase responsivity; also, improve preamplifier signal-to-noise figures of merit. 
(6) Continue work on development of polymeric ultraviolet sensors; develop adequate instrumentation to measure ultraviolet pyroelectric response.

(7) Continue work on development of polymeric pyroelectric sensors having selective wavelength responses.

\section{REFERENCES}

[1] Bazhenov, V.A., Piezoelectric Properties of Wood (Consultants Bureau Enterprises, Inc., New York, 1961).

[2] Cohen, J., and Edelman, S., Direct Piezoelectric Effect in Polyvinylchloride Films, J. Appl. Phys. 42, pp. 893-894 (February 1971).

[3] Cohen, J., and Edelman, S., Piezoelectric Effect in Oriented Polyvinylcholoride and Polyvinyl Fluoride, J. Appl. Phys. 42, pp. 3072-3074 (July 1971).

[4] Cohen, J., Vezzetti, C.F., and Edelman, S., Polymeric Pyroelectric Detectors, Proc. of the Special Meeting on the Physics of Detectors, U.S. Naval Training Device Center, Orlando, FL, March 15, 1972, pp. 113-117, (Infrared Information and Analysis Center, Willow Run Laboratories, U. of Mich., Ann Arbor, MI, 1972).

[5] Glass, A.M., McFee, J.H., and Bergman, J.G., Jr., Pyroelectric Properties of Polyvinylidene Fluoride and Its Use for Infrared Detection, J. App1. Phys. 42, No. 13, pp. 5219-5222 (December 1971).

[6] Phelan, R.J., Jr., Mahler, R.J., and Cook, A.R., High D* Pyroelectric Polyvinyl Fluoride Detectors, App1. Phys. Letters 19, No. 9, pp. 337338 (November 1971).

[7] Fukada, E., and Takashita, S., Piezoelectric Effect in Polarized Poly(Vinylidene Fluoride), Jpn. J. Appl. Phys. 8 , pp. 960-961 (July 1969).

[8] Kawai, H., The Piezoelectricity of Poly(Vinylidene Fluoride), Jpn. J. App1. Phys. 8 , pp. 975-976 (July 1969).

[9] Lando, J.B., 01f, H.G., and Peterlin, A., Nuclear Magnetic Resonance and $X$-Ray Determination of the Structure of Poly (Vinylidene Fluoride), J. Poly. Sci. 4, Part A-1, pp. 941-951 (Apri1 1966).

[10] Zbinden, R., Infrared Spectroscopy of High Polymers, pp. 29-30 (Academic Press, New York, NY, 1964).

[11] Edelman, S., Grisham, L.R., Roth S.C., and Cohen, J., Improved Piezoelectric Effect in Polymers, J. Acoust. Soc. Amer. 48, No. 5 (Part 1) pp. 1040-1043 (November 1970). 
[12] Engineering Design Handbook - Infrared Military Systems, Part 1 , Pp. 3-126 et seq, AMCP 706-127 (U.S. Army Material Command 1971). 
㞬

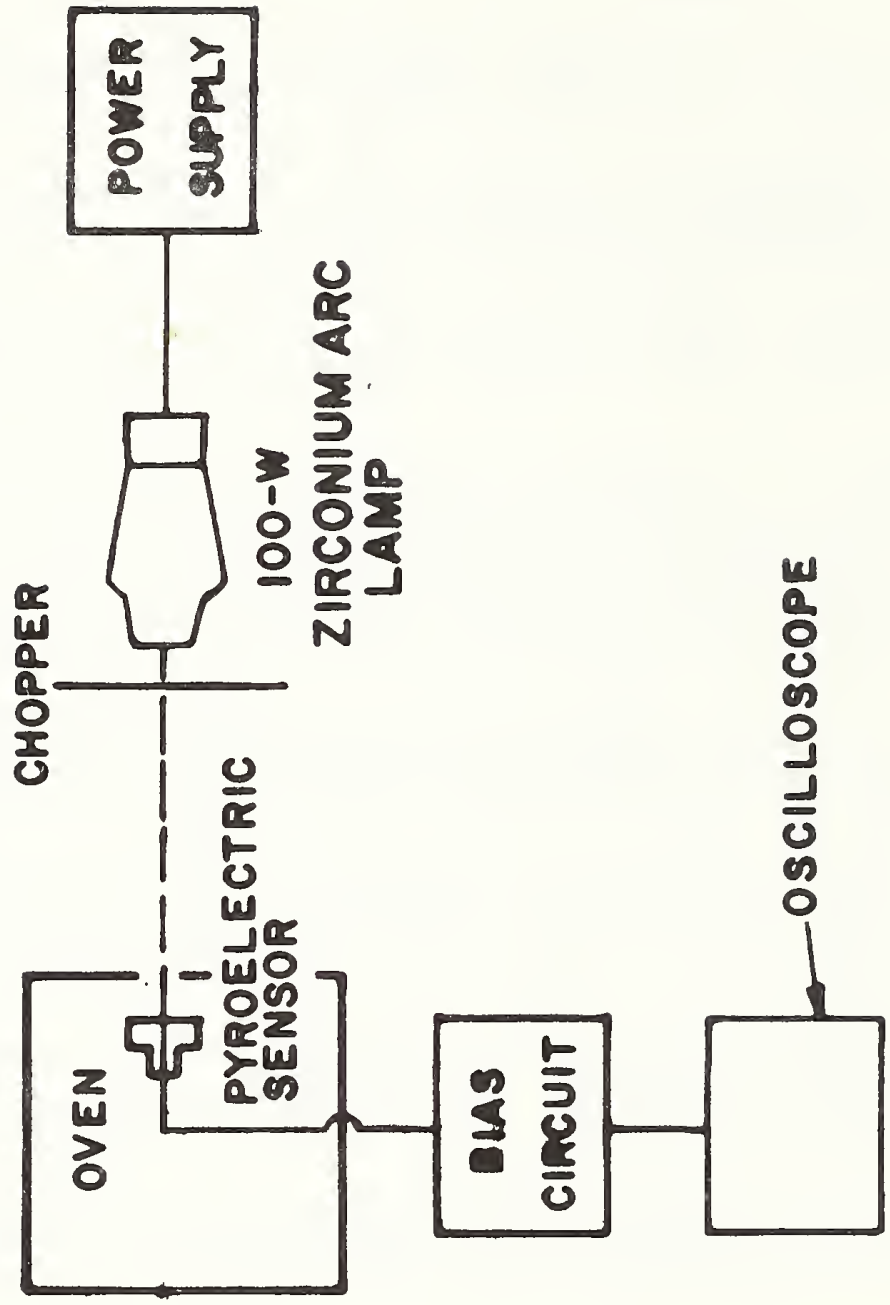

出

름

은

은

보 웅

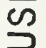

운

$\vec{b}$ o

?

山

운

क

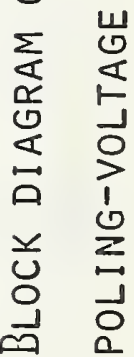

$\ddot{\ddot{r}}$

$\underset{\square}{\square}$ 
SEMITRANSPARENT ELECTRODE

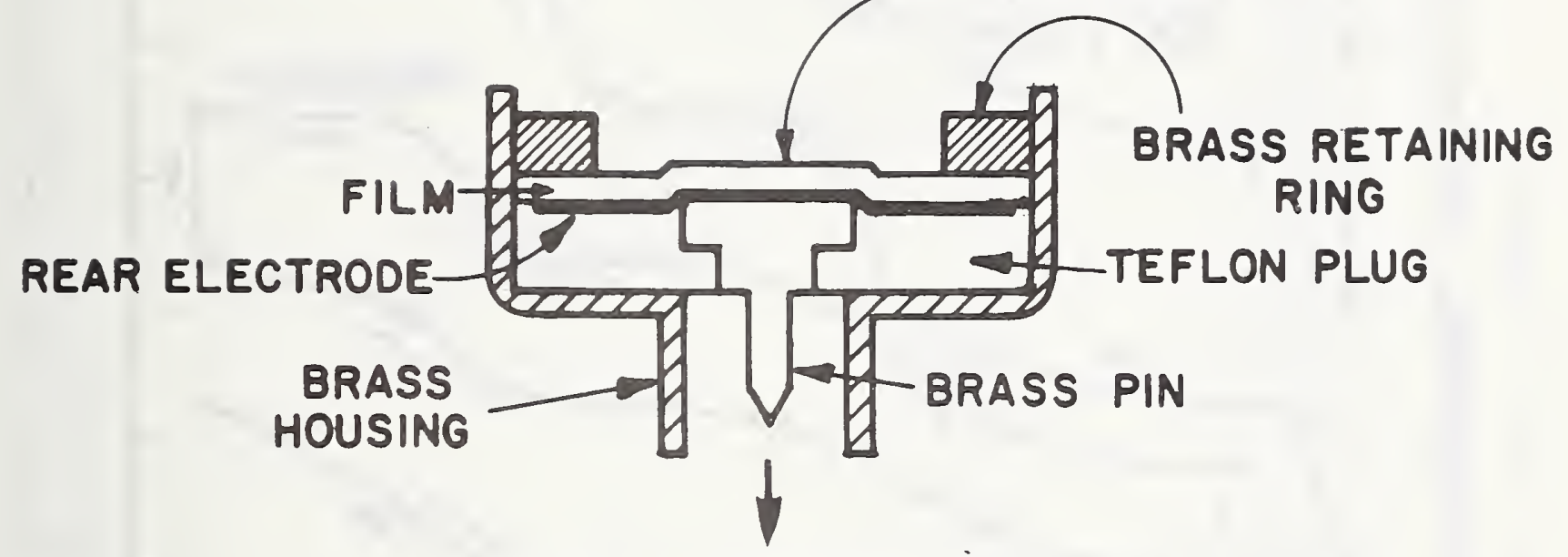

TO BNC CONNECTOR

Figure 2: Poling fixture, A Vertical CROSS SECTION IS SHOWN: THE FIXTURE IS RADIALLY SYMMETRIC WITH RESPECT TO A VERTICAL AXIS THROUGH THE PIN. THE BRASS RING USED TO RETAIN THE POLYMER FILM IS A PRESS FIT INTO THE HOUSING. THE LOWER END OF THE BRASS PIN IS CONNECTED TO THE CENTER CONDUCTOR OF A BNC CONNECTOR: THE HOUSING, TO THE CONNECTOR SHIELD, THE BROADENED HEAD AT THE UPPER END OF THE PIN IS WEAKLY BONDED TO THE REAR ELECTRODE, WHICH HAS A SMALLER DIAMETER THAN THE UPPER ELECTRODE SO THAT NO ELECTRICAL CONTACT IS MADE BETWEEN THE REAR ELECTRODE AND THE HOUSING, 


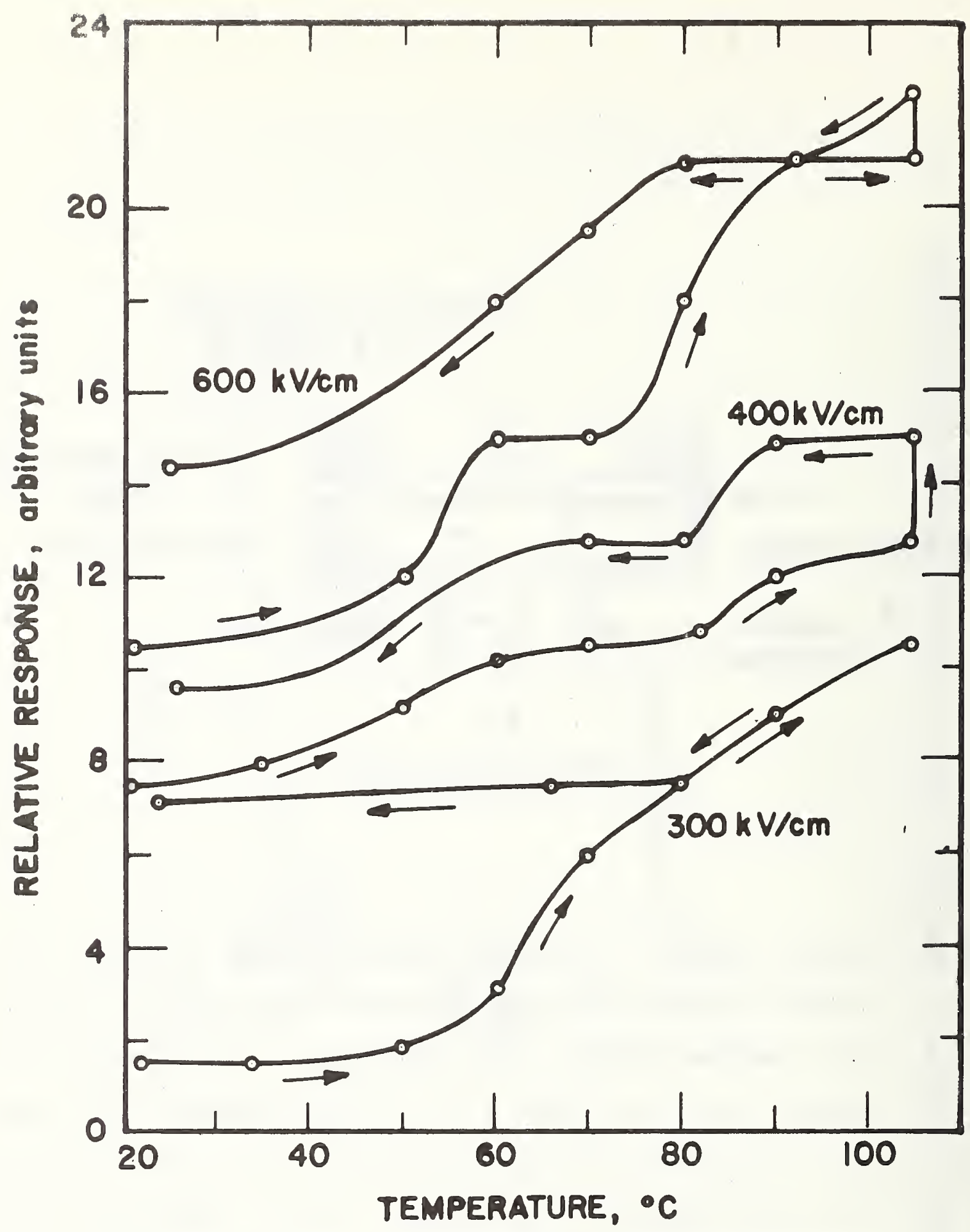

Figure 3: ReLATIVE RESPONSE OF A PVF 2 SAMPLE AS A FUNCTION OF POLING TEMPERATURE FOR THREE POLING FIELDS, ARROWS INDICATE THE DIRECTION OF THE CHANGE IN TEMPERATURE FOR A GIVEN PORTION OF THE POLING CYCLE. THE RESPONSE WAS MEASURED AS DESCRIBED IN THE TEXT, 


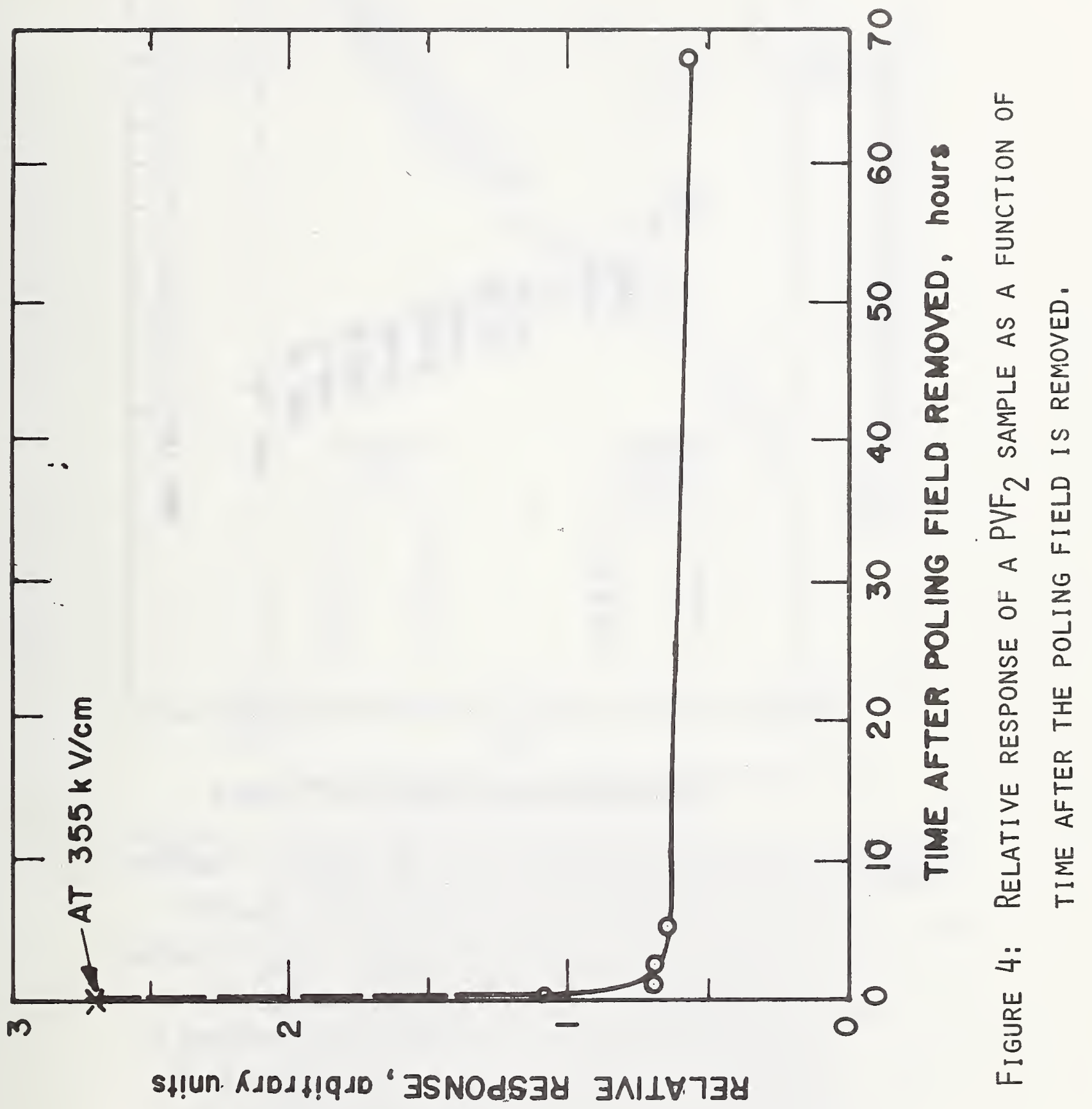




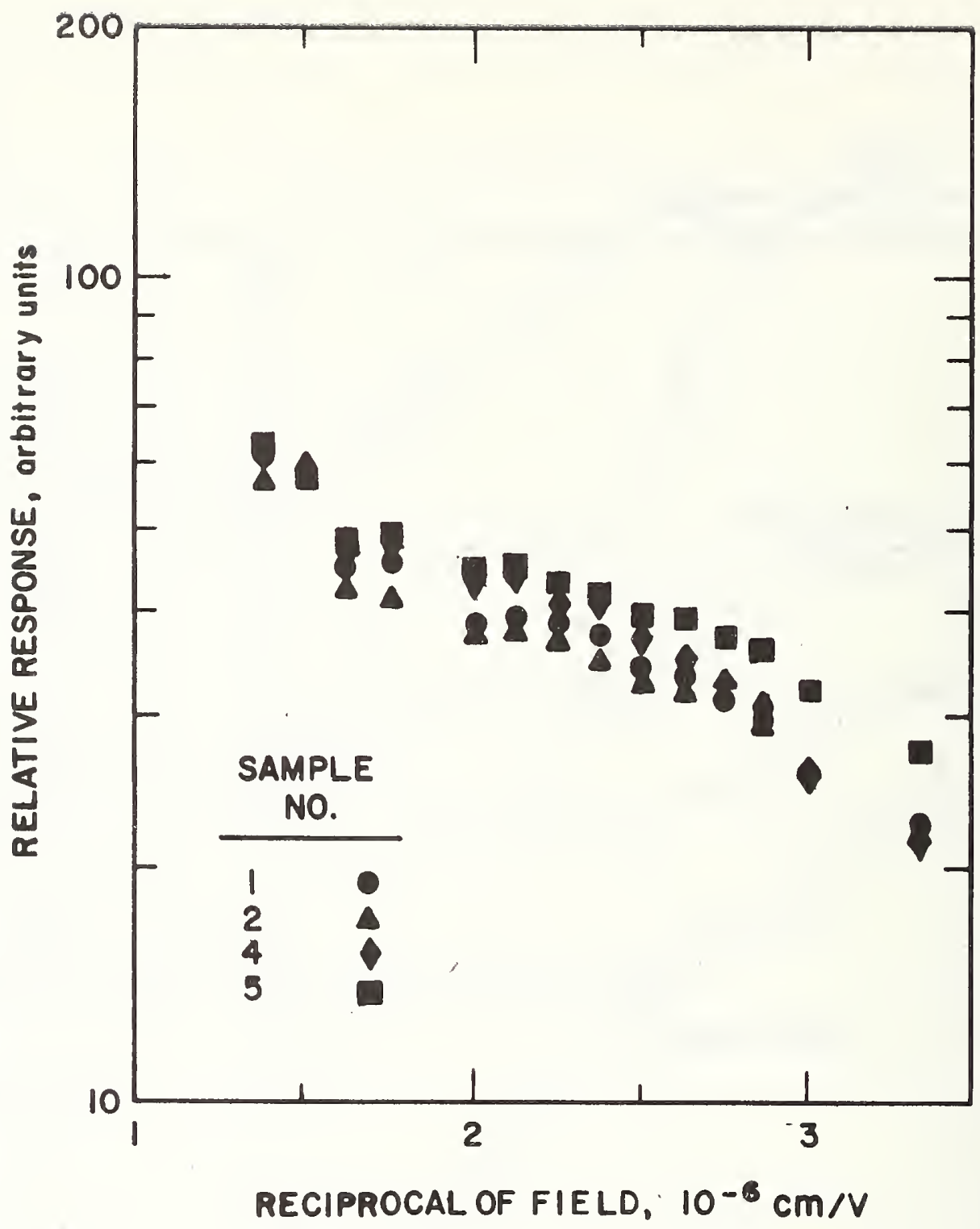

Figure 5: ReLATIVE POLYMER PYROELECTRIC RESPONSE AS A FUNCTION OF THE RECIPROCAL OF THE POLING FIELD. RELATIVE RESPONSE IS ON A LOGARITHMIC SCALE. THE FOUR SAMPLES WERE TAKEN FROM A SINGLE PIECE OF 6- $\mu$ M PVF 2 FILM. THE PROCESSING FOR THE FOUR SAMPLES WAS INTENDED TO BE IDENTICAL: ALL WERE POLED AT THE SAME TIME IN the same oven. Poling temperature was $90^{\circ} \mathrm{C}$. The RELATIVE RESPONSE MAY BE CONSIDERED TO BE PROPORTIONAL TO THE PYROELECTRIC RESPONSIVITY, WITH THE SAME PROPORTIONALITY FACTOR FOR FIGURES 5-9. THE MEASURING FREQUENCY WAS $10 \mathrm{~Hz}$, THE BLACKBODY TEMPERATURE $500 \mathrm{~K}$, AND THE DISTANCE FROM THE BLACKBODY APERTURE TO THE SENSOR WAS $50 \mathrm{~cm}$. THE EQUiVALENT NOISE BANDWIDTH WAS ADJUSTED TO BE $1 \mathrm{~Hz}$. 


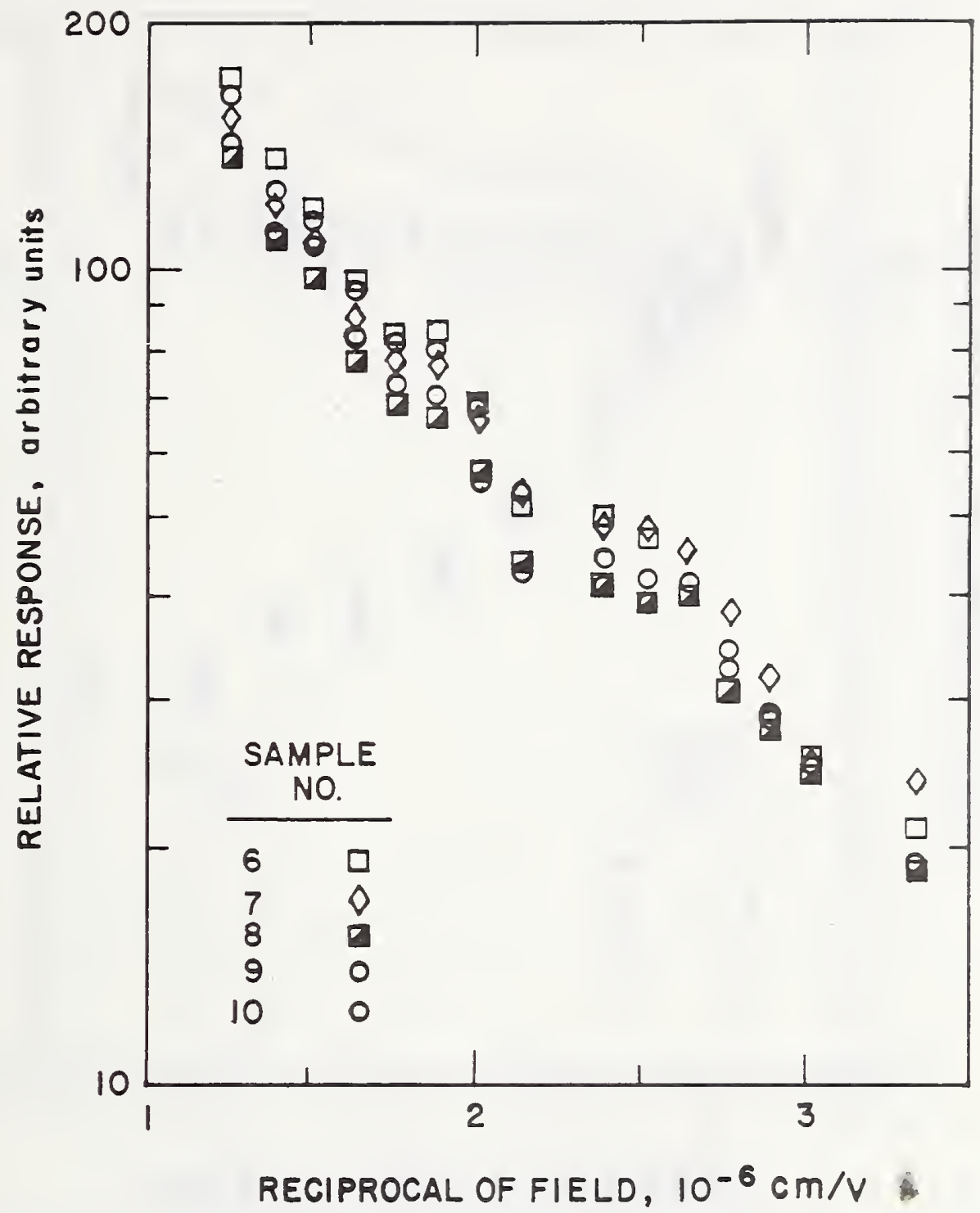

Figure 6: ReLATIVE POLYMER PYROELECTRIC RESPONSE AS A FUnCTION OF THE RECIPROCAL OF tHE POLING FiELD, ReLATIVE RESPONSE Is on a Logarithmic scale. The five samples Were taken FROM A SINGLE PIECE OF 6- $\mu$ M PVF 2 FILM. THE PROCESSING FOR THE FIVE SAMPLES WAS INTENDED TO BE IDENTICAL: ALL were poled at the same time in the same oven, Poling TEMPERATURE WAS $110^{\circ} \mathrm{C}$. THE RELATIVE RESPONSE MAY BE CONSIDERED TO BE PROPORTIONAL TO THE PYROELECTRIC RESPONSIVITY, WITH THE SAME PROPORTIONALITY FACTOR FOR FIgURES 5-9. THE MEASURING FREQUENCY WAS $10 \mathrm{~Hz}$, the BLACKBODY TEMPERATURE $500 \mathrm{~K}$, AND THE DISTANCE FROM THE BLACKBODY APERTURE TO THE SENSOR WAS $50 \mathrm{~cm}$. THE EQUIVALENT NOISE BANDWIDTH WAS ADJUSTED TO BE $1 \mathrm{~Hz}$. 


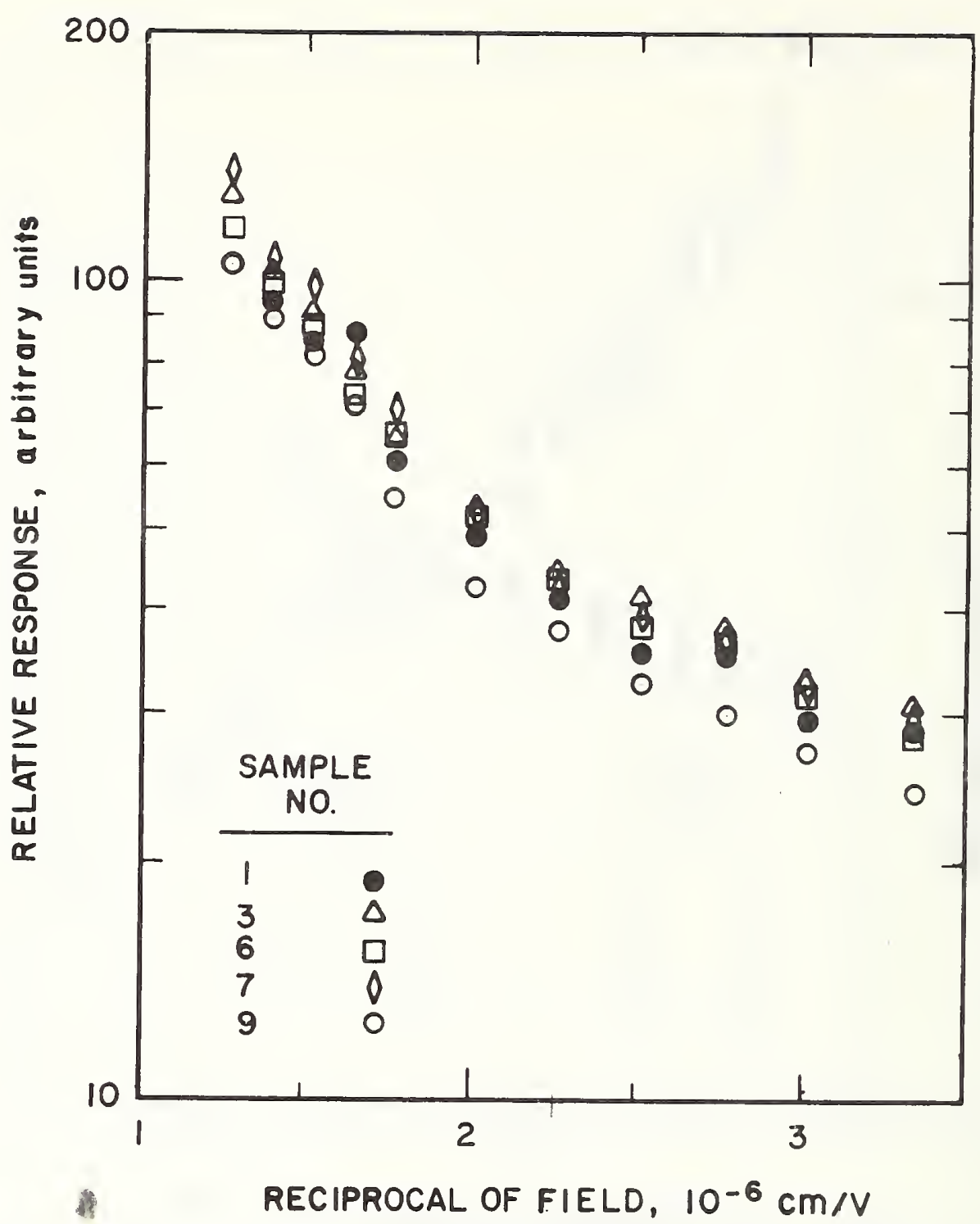

FigURE 7: RELATIVE POLYMER PYROELECTRIC RESPONSE AS A FUNCTION OF THE RECIPROCAL OF THE POLING FIELD, ReLATIVE RESPONSE IS ON A LOgarithmic SCALE. THE FIVE SAMPLES WeRe taken FROM A SINGLE PIECE OF 6- $\mu$ M PVF 2 FILM. THE PROCESSING FOR THE FIVE SAMPLES WAS INTENDED TO BE IDENTICAL: ALL were poled at the same time in the same oven, Poling temperature WAS $130^{\circ} \mathrm{C}$. THE kelative response may BE CONSIDERED TO BE PROPORTIONAL TO THE PYROELECTRIC RESPONSIVITY, WITH THE SAME PROPORTIONALITY FACTOR FOR Figures 5-9. THE MEASURING FREQUenCy WAS $10 \mathrm{~Hz}$, the BLACKBODY TEMPERATURE $500 \mathrm{~K}$, AND THE DISTANCE FROM THE BLACKBODY APERTURE TO THE SENSOR WAS $50 \mathrm{cM}$. THE EQUIVALENT NOISE BANDWIDTH WAS ADJUSTED TO BE $1 \mathrm{~Hz}$. 


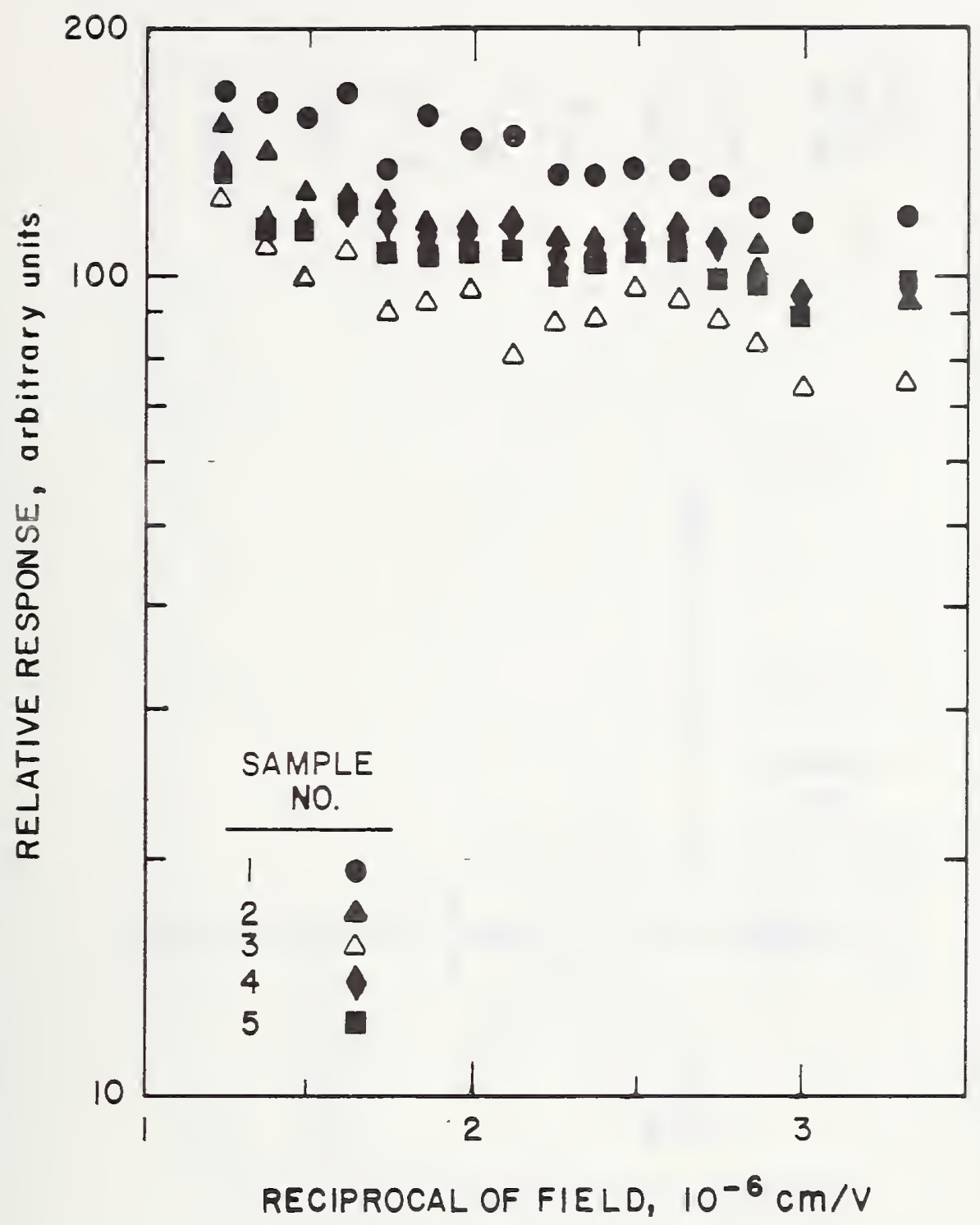

Figure 8: RELATIVE POLYMER PYROELECTRIC RESPONSE AS A FUNCTION OF THE RECIPROCAL OF THE POLING FIELD, RELATIVE RESPONSE IS ON A LOGARITHMIC SCALE. THE FIVE SAMPLES WERE TAKEN

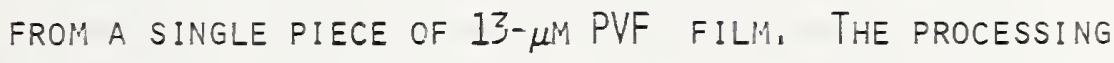
FOR THE FIVE SAMPLES WAS INTENDED TO BE IDENTICAL: ALL Were poled at the same time in the same oven, Poling temperature was $90^{\circ} \mathrm{C}$. The Relative REsponse MAY BE CONSIDERED TO BE PROPORTIONAL TO THE PYROELECTRIC RESPONSIVITY, WITH THE SAME PROPORTIONALITY FACTOR FOR FIGURES 5-9, THE MEASURING FREQUenCY W'AS $10 \mathrm{~Hz}$, THE BLACKBODY TEMPERATURE $500 \mathrm{~K}$, AND THE DISTANCE FROM THE BLACKBODY APERTURE TO THE SENSOR WAS $50 \mathrm{CM}$. THE EQUIVALENT NOISE BANDWIDTH WAS ADJUSTED TO $1 \mathrm{~Hz}$, 


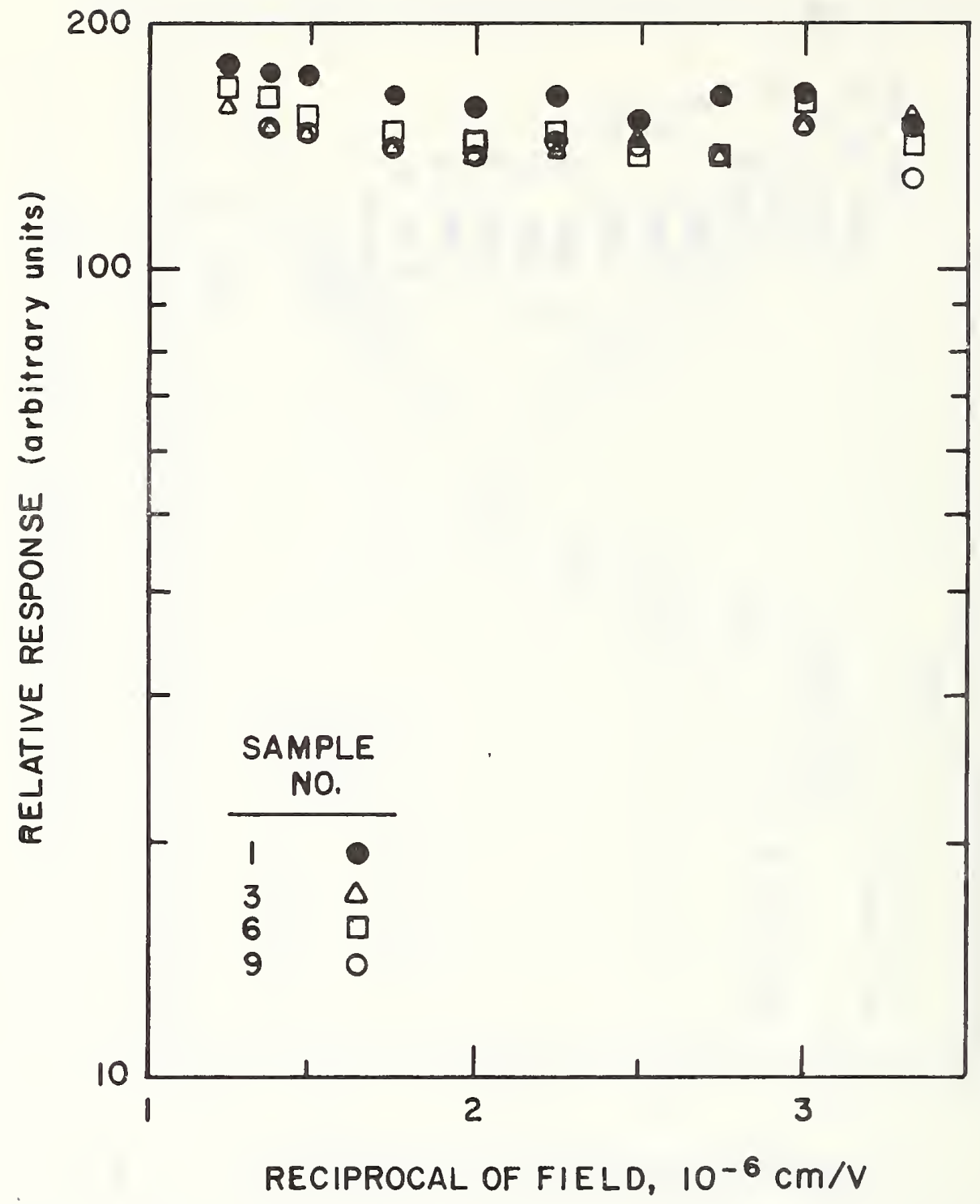

Figure 9: Relative polymer pyroelectric response as a function of the ReCiprocal of the poling field, Relative Response IS ON A LOGARITHMIC SCALE. THE FOUR SAMPLES WERE TAKEN from a Single Piece of 13- $\mu$ M PVF film. The PROCESSing FOR THE FOUR SAMPLES WAS INTENDED TO BE IDENTICAL: ALL Were poled at the same time in the same oven, Poling TEMPERATURE WAS $110^{\circ} \mathrm{C}$. THE RELATIVE REsPONSE MAY BE CONSIDERED TO BE PROPORTIONAL TO THE PYROELECTRIC RESPONSIVITY WITH THE SAME PROPORTIONALITY FACTOR FOR FIgURES 5-9, THE MEASURING FREQUENCY WAS $10 \mathrm{~Hz}$, THE BLACKBODY TEMPERATURE $500 \mathrm{~K}$, AND THE DISTANCE FROM THE BLACKBODY APERTURE TO THE SENSOR WAS $50 \mathrm{~cm}$. THE EQUIVALENT NOISE BANDWIDTH WAS ADJUSTED TO BE $1 \mathrm{~Hz}$. 


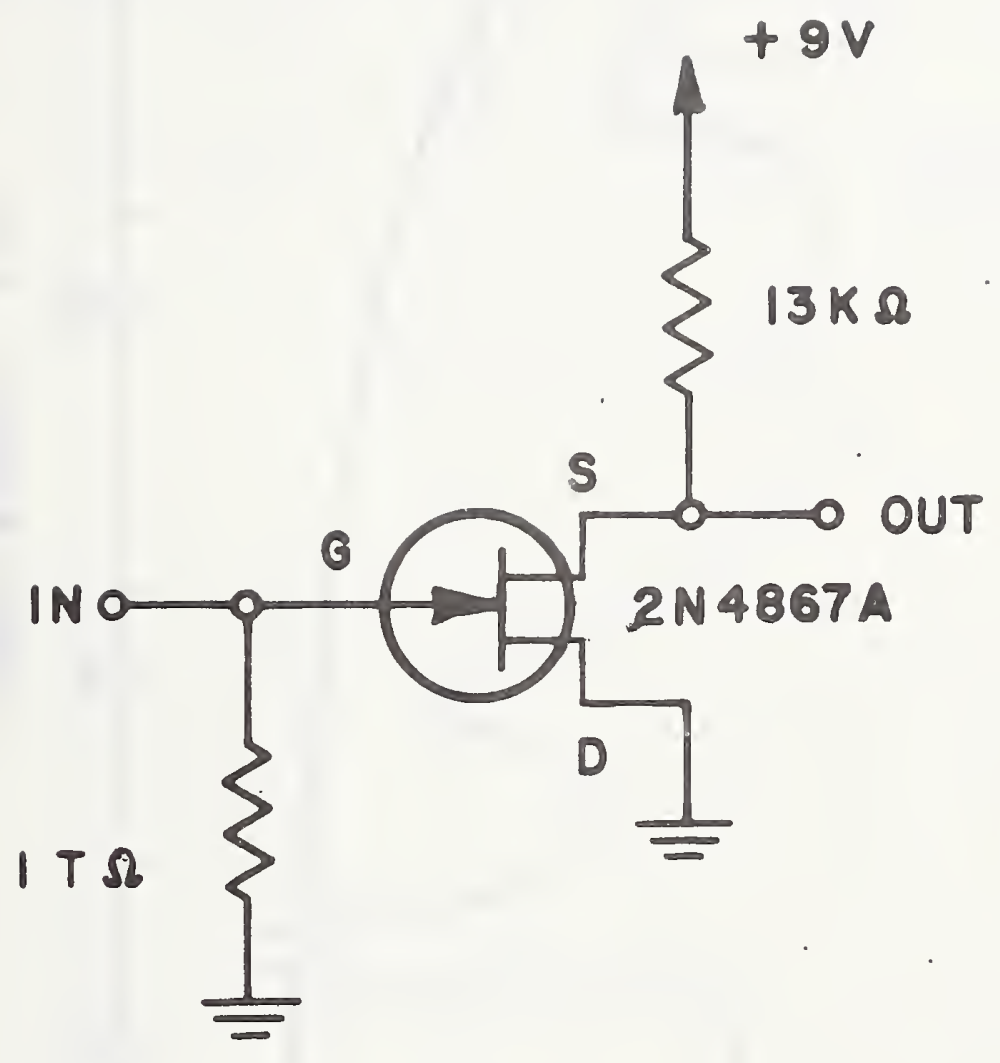

Figure 10: CiRCUit OF VOLTAge PREAMPLifiER USED IN RELATIVE PYROELECTRIC RESPONSE MEASUREMENTS, 


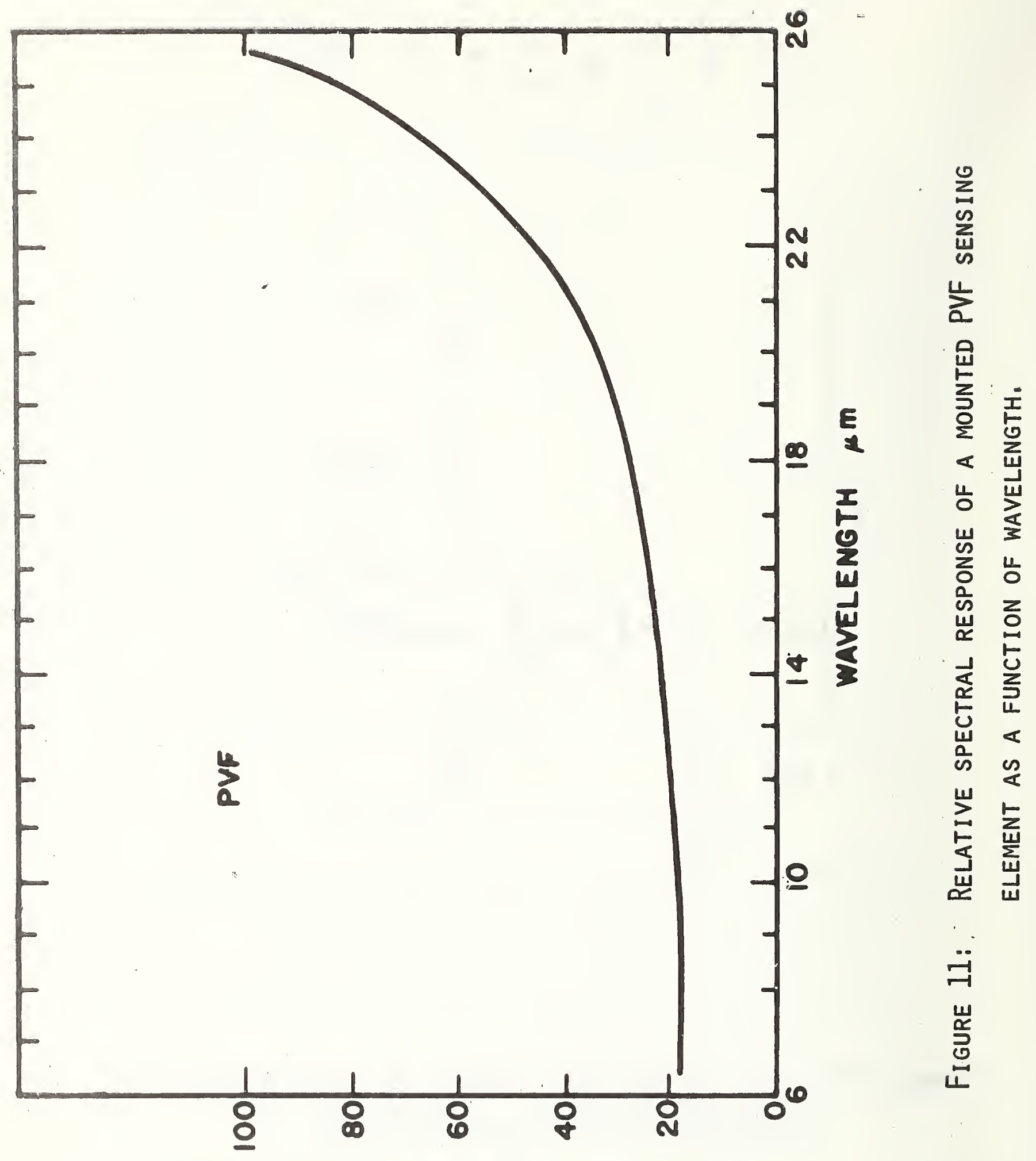

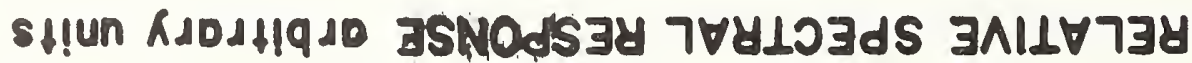




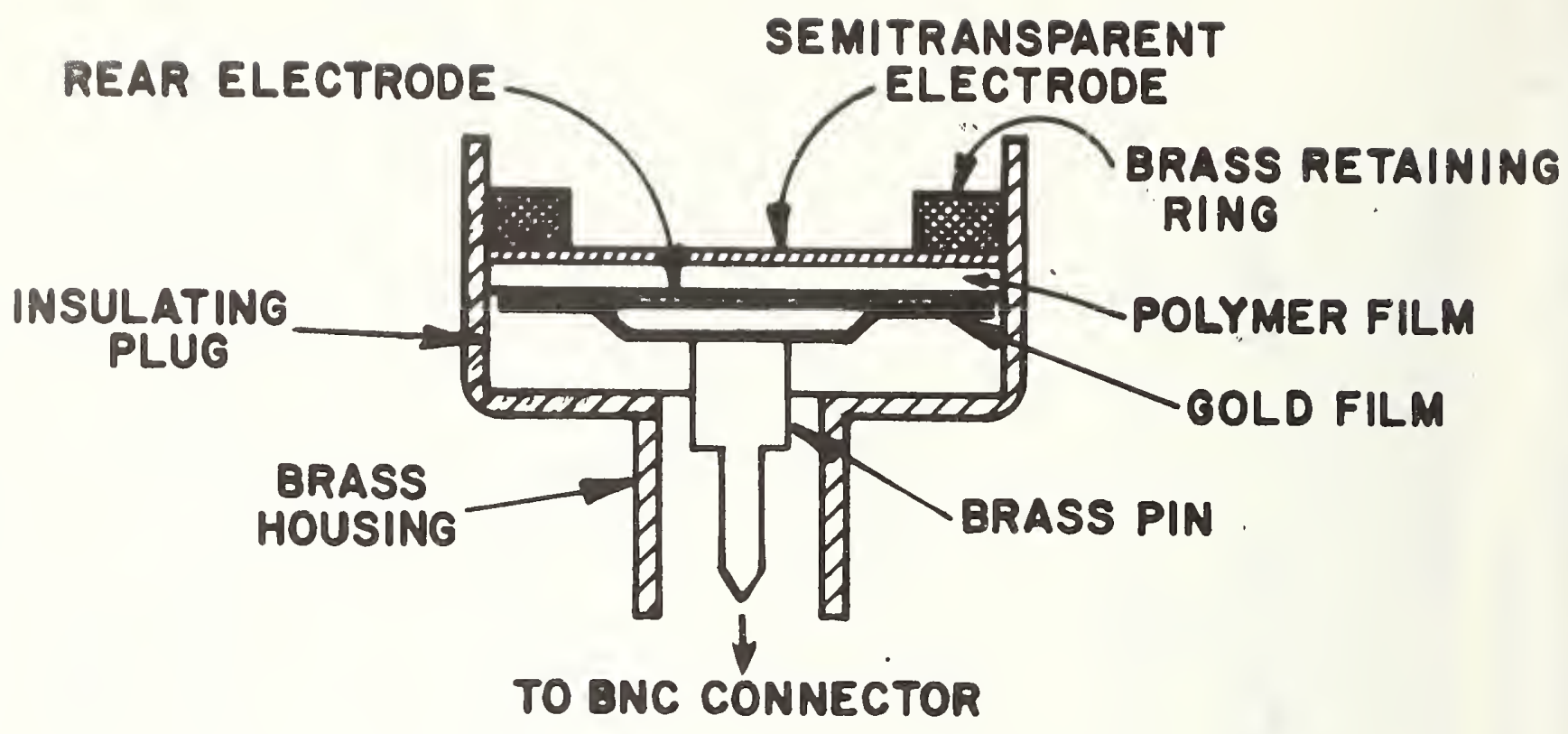

FigURE 13: SENSOR CONSTRUCTION. A VERTICAL CROSS SECTION IS SHOWN: THE SENSOR IS RADIALLY SYMMETRIC WITH RESPECT TO A VERTICAL AXIS THROUGH THE PIN, THE BRASS RING USED TO RETAIN THE POLYMER-FILM SENSING ELEMENT IS A PRESS FIT INTO THE HOUSING, THE LOWER END OF THE BRASS PIN IS CONNECTED TO THE CENTER CONDUCTOR OF A BNC CONNECTOR: THE HOUSING, TO THE CONNECTOR SHIELD, THE TOP OF THE ENLARGED PART OF THE PIN IS FLUSH WITH AN IDENTATION IN THE TOP SURFACE OF THE INSULATING PLUG; AN EVAPORATED GOLD FILM COVERS PIN AND PLUG, EXCEPT FOR A NARROW RING at the PLUg CIRCUMfERENCE, EleCtrical CONTACT TO THE REAR ELECTRODE IS MADE VIA THE GOLD FILM TO THE PIN, THIS DESIGN, COMPARED TO THAT OF FIGURE 2, PROVIDES IMPROVED THERMAL ISOLATION FROM THE BRASS PIN, WHICH OTHERWISE SERVES AS A HEAT SINK, 

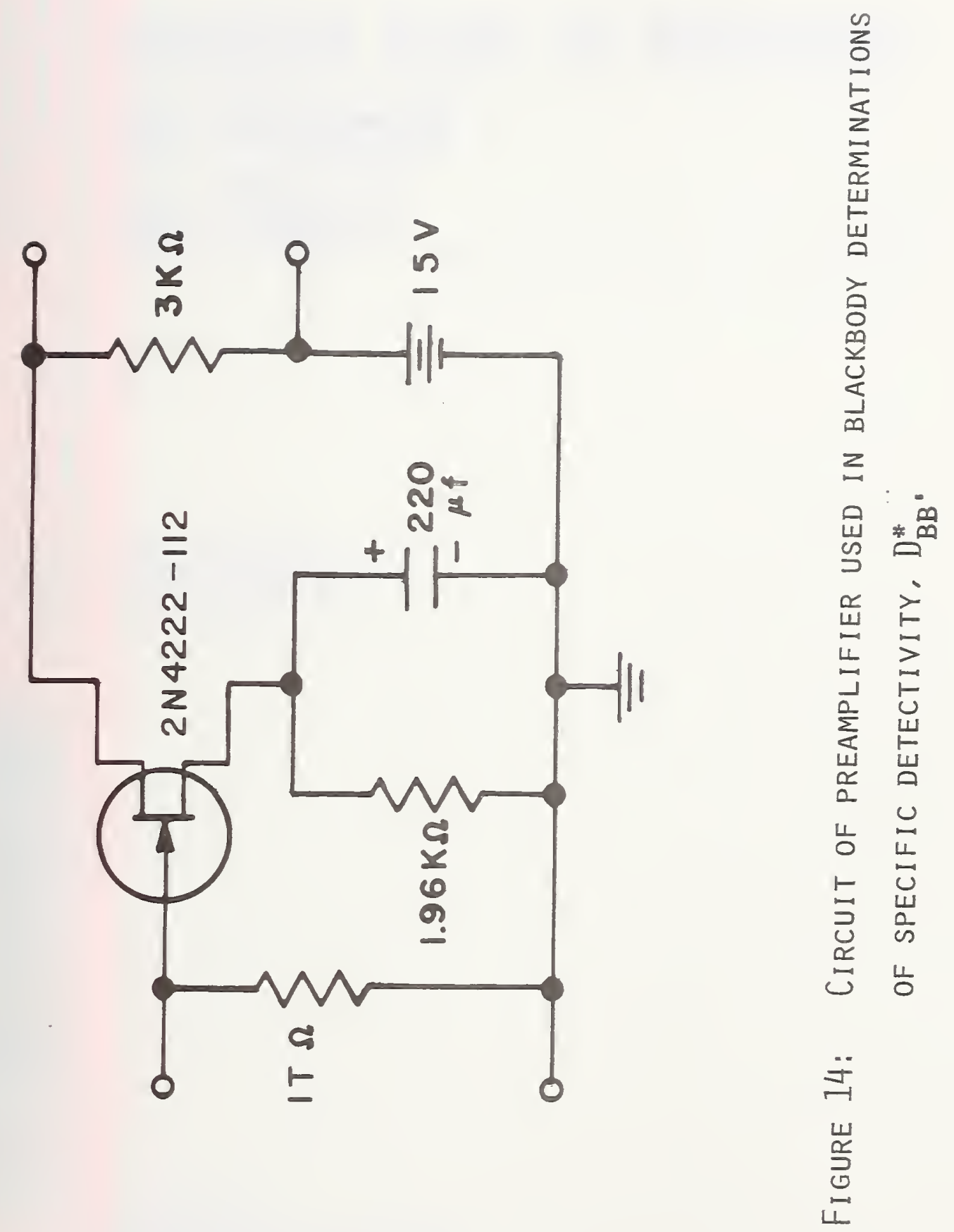
